\title{
Room temperature hydrogen storage in defective single-walled carbon nanotubes: a molecular dynamics study
}

\author{
M. Garg ${ }^{1}$, S. Ghosh ${ }^{\dagger, 2}$, V. Padmanabhan ${ }^{3}$ \\ ${ }^{\dagger}$ sarbani.ghosh@pilani.bits-pilani.ac.in \\ ${ }^{1}$ Department of Chemical Engineering, Indian Institute of Technology, Kharagpur, West Bengal, 721302, India \\ ${ }^{2}$ Department of Chemical Engineering, Birla Institute of Technology and Science (BITS), \\ Pilani Campus, Vidya Vihar, Pilani, 333031, Rajasthan, India \\ ${ }^{3}$ Department of Chemical Engineering, Tennessee Technological University, Cookeville, TN, 38505, USA
}

Hydrogen has the potential to be an alternative source of energy. However, most of the research on hydrogen storage carried out in the past is based on low temperature $(<80 \mathrm{~K})$ whereas storage near room temperature is desired. Here, we report room-temperature hydrogen storage capacity of defective single-walled carbon nanotubes (SWCNT) investigated using molecular dynamics simulations and density functional theory. Four different types of defective SWCNTs are considered to study room temperature hydrogen storage. We observed maximum adsorption capacity of SWCNT with 5 and 8-membered ring defects, namely, D1. The SWCNT with other three defects studied here, Stone-Wales with 5- and 7-membered ring defect (D2), 5-membered ring defect (D3), and 3-, 5- and 8-membered ring defect (D4) have negative adsorption effect compared to the defect-free SWCNT. The highest gravimetric capacity of $1.82 \mathrm{wt} \%$ is found for the D1 defective SWCNT at room temperature, $298 \mathrm{~K}$ and $140 \mathrm{~atm}$. The DFT calculations show that hydrogen adsorption strongly depends on the type of defect where the 8-membered ring has the highest adsorption energy and the 3-membered ring has the lowest adsorption energy. A combination of 5- and 8-membered defective rings can increase hydrogen adsorption significantly even at room temperature.

Keywords: single-walled carbon nanotubes, room temperature hydrogen adsorption, defect, molecular dynamics simulations, density functional theory.

УДК: 538.9

\section{Хранение водорода при комнатной температуре в дефектных одностенных углеродных нанотрубках: исследование молекулярной динамики}

\author{
Гарг M. ${ }^{1}$, Гош C. ${ }^{\dagger, 2}$, Падманабхан B. ${ }^{3}$ \\ ${ }^{1}$ Кафедра химического машиностроения, Индийский технологический институт, \\ Харагпур, Западная Бенгалия, 721302, Индия \\ ${ }^{2}$ Кафедра химического машиностроения, Институт технологий и науки Бирла (BITS), \\ кампус Пилани, Видья Вихар, Пилани, 333031, Раджастан, Индия
}

${ }^{3}$ Кафедра химического машиностроения, Технологический университет Теннесси, Куквилль, Теннесси, 38505, США

Водород может стать альтернативным источником энергии. Однако большинство исследований по хранению водорода, проведенных в прошлом, основано на хранении при низких температурах (<80 К), тогда как желательным является хранение при комнатной температуре. В данной статье мы сообщаем о способности накапливать водород при комнатной температуре в дефектных однослойных углеродных нанотрубках (ОУНТ), исследованных с помощью моделирования молекулярной динамики и теории функционала плотности (ТФП). Рассмотрены четыре различных типа дефектных ОУНТ для изучения хранения водорода при комнатной температуре. Нами наблюдалась максимальная адсорбционная способность ОУНT с 5- и 8-членными кольцевыми дефектами, а именно D1. OУНT с тремя другими изученными здесь дефектами: дефект Стоуна-Уэльса с 5- и 7-членным кольцевым дефектом (D2), 5-членный кольцевой дефект (D3) и 3-, 5- и 8-членный кольцевой дефект (D4) имеют отрицательный адсорбционный 
эффект по сравнению с бездефектной ОУНТ. Наибольшая гравиметрическая емкость 1.82 мас.\% обнаружена для ОУНТ с дефектом D1 при комнатной температуре, 298 К и 140 атм. Расчеты ТФП показывают, что адсорбция водорода сильно зависит от типа дефекта, где 8-членное кольцо имеет самую высокую энергию адсорбции, a 3-членное кольцо имеет самую низкую энергию адсорбции. Комбинация 5- и 8-членных дефектных колец может значительно увеличить адсорбцию водорода даже при комнатной температуре.

Ключевые слова: однослойные углеродные нанотрубки, адсорбция водорода при комнатной температуре, дефект, молекулярнодинамическое моделирование, теория функционала плотности.

\section{Introduction}

To fulfill the growing demand of energy and to reduce the environmental pollution caused by the extreme use of conventional carbon-based fossil fuels, hydrogen has been found as a clean alternative source of energy without any carbon emissions. However, the efficient on-board hydrogen storage and release systems are currently limiting the widespread utilization of hydrogen as a fuel in our daily life. The U.S. Department of Energy (DOE) has set a hydrogen storage target of $4.5 \mathrm{wt} . \%$ gravimetric capacity and $30 \mathrm{~g} \mathrm{H}_{2}$ /liter volumetric capacity at operating temperature ranging between $233-333 \mathrm{~K}[1,2]$. Several studies show that in comparison to other conventional methods, physical adsorption of hydrogen gas molecules on a solid adsorbent is a promising approach to achieve the ultimate goal of DOE [3-8]. The light-weight carbon-based materials have been found to overcome the disadvantage of heavy system weight and hence they are promising to meet the gravimetric storage target [9]. Among all the hydrogen adsorbents, carbon nanotubes (CNT) have been extensively studied in the past and have been found to meet the storage targets at cryogenic temperatures $(<80 \mathrm{~K})[10-12]$. However, storage capacity significantly decreases at room temperature as the governing force i.e., van der Waals interaction decreases with temperature. Finding a suitable hydrogen adsorbent which will be efficient enough to reach the DOE target at the ambient temperature is crucial.

The physical modification of the adsorbent affects the interaction energy towards the hydrogen gas molecules. For instance, foreign atom doped CNTs have higher hydrogen adsorptivity than pure nanotubes which indicates that structural changes can affect the adsorptivity $[13,14]$. Gammairradiation which causes structural changes and defect formation in the carbon nanotubes can increase the hydrogen storage capacity [15]. Crumpled graphene can increase the hydrogen storage capacity which is another example of the effect of structural modification on hydrogen storage [16]. Our previous study suggests that presence of defects may increase the hydrogen storage capacity depending upon the type of defects [17]. A study of Zhou and Shi also shows that Stone-Wales defect can be beneficial to adsorb some foreign atoms [18]. Interestingly, incorporating a particular type of defect, namely the Stone-Wales 5, 8 defect [19-21], hydrogen storage capacity above the DOE target can be reached at a low temperature of $80 \mathrm{~K}$ [17]. However, the effectiveness of the defect on hydrogen storage at room temperature is unknown. As the storage at room temperature is desired, it is important to study the effect of the defects on hydrogen storage at room temperature.
Widespread implementation of hydrogen-based energy is mainly limited by lack of effective storage system at ambient conditions and therefore, room temperature study is essential which is missing to a large extent. Here, we report room temperature hydrogen storage capacity of defective single-walled carbon nanotubes (SWCNT) using molecular dynamics (MD) simulations. We calculate adsorption energy using density functional theory (DFT) to analyze the effects of different types of defects. In this approach, we vary the type of the defect which is characterized by the number of carbon atoms present in one ring.

\section{Model and Methods}

We considered four types of defective (D1, D2, D3 and D4) nanotubes to study the hydrogen adsorption, as shown in Fig. 1. All molecular dynamics (MD) simulations were carried out using LAMMPS molecular dynamics simulations package [22] and density functional theory (DFT) calculations were done using Quantum-Espresso [23]. During the MD simulations, hydrogen molecules were considered as single spheres for simplicity and the nanotube was constructed considering all carbon atoms. Hydrogen molecules were allowed to move while the nanotube was fixed throughout the simulation at its initial position to prevent floating of the SWCNT. 4000 hydrogen molecules and one SWCNT were placed inside an $80 \AA$ cubic box as shown in Fig. 2 b. Periodic boundary conditions were applied in all the directions. Newton's equation of motion was integrated for $5 \mathrm{~ns}$ with a timestep of $1 \mathrm{fs}$ using velocityVerlet algorithm in the isothermal-isobaric (NPT) ensemble. Interactions for physisorption were taken care using van der Waals interaction which was modeled by the widely used Lennard-Jones 12-6 potential model. Interaction parameters for carbon atoms and hydrogen molecules have been tabulated in Table 1 , where $\varepsilon$ is the energy parameter, $\sigma$ is the interaction diameter and $r_{c}$ is the cut-off distance where potential was smoothly switched off $[24,25]$. Physisorption of hydrogen molecules was investigated firstly using armchair, chiral and zigzag SWCNT and then introducing defects in SWCNTs. Length of the nanotube was kept fixed at a finite length of $40 \AA$. The temperature and pressure were kept

Table 1. Lennard-Jones interaction parameters for carbon atom and hydrogen molecules.

\begin{tabular}{|c|c|c|c|}
\hline & $\varepsilon(\mathrm{kcal} / \mathrm{mol})$ & $\sigma(\AA)$ & $r_{\mathrm{c}}(\AA)$ \\
\hline $\mathrm{H}_{2}-\mathrm{H}_{2}$ & 0.0733325 & 2.928 & 8.784 \\
\hline $\mathrm{C}-\mathrm{C}$ & 0.0553453 & 3.430 & 10.290 \\
\hline $\mathrm{C}-\mathrm{H}_{2}$ & 0.0636932 & 3.179 & 9.537 \\
\hline
\end{tabular}


fixed throughout the simulations at $298 \mathrm{~K}$ and 140 atm, respectively. All the analyses have been done using the system, chopped from top and bottom in $z$-axis along SWCNT's length to neglect the edge effect and the hydrogen molecules present only in the chopped section have been considered for analysis. In this way, we have neglected the effect of a finite length of the nanotube. In order to calculate the radial density profiles, $\rho(r)$ of hydrogen molecules perpendicular to the central axis of SWCNT ( $z$-axis), the system was divided into several cylindrical bins and hydrogen density was calculated by counting the number of hydrogen molecules present in each bin divided by volume of that bin, as shown in Eq. (1):

$$
\rho(r)=\frac{N}{\pi l\left[(r+\delta r)^{2}-r^{2}\right]},
$$

where, $N$ is the total number of hydrogen molecules present in a cylindrical bin, $\delta r$ is the bin width, $r$ is the distance from the center axis of the nanotube, and $l$ is the length of the nanotube. Next, we estimated the gravimetric hydrogen adsorption in weight basis (wt.\%) by Eq. (2):

$$
\text { Gravimetriccapacity }=\frac{m_{\mathrm{H}}}{m_{\mathrm{H}}+m_{\text {adsorbent }}} \times 100,
$$

where $m_{\mathrm{H}}$ is the total mass of adsorbed hydrogen and $m_{\text {adsorbent }}$ is the mass of adsorbent.
Diameter $(D)$ of the SWCNT was calculated using Eq. (3):

$$
D=\frac{\sqrt{3}}{\pi} R_{\mathrm{C}-\mathrm{C}}\left(a^{2}+a b+b^{2}\right)^{\frac{1}{2}},
$$

where $R_{\mathrm{C}-\mathrm{C}}$ is the equilibrium bond length of graphene i.e. $1.42 \AA$ and $a, b$ are the chiral indices. Defect was inserted in CNT by removing or modifying one or two carbon atoms and forming different combinations of several $n$-membered rings, where $n$ varies from 3 to 8 .

We used DFT calculations to optimize the structures of the nanotubes and to calculate the adsorption energies of hydrogen molecules for different $n$-membered rings using the plane-wave basis set as implemented in QuantumEspresso [15]. Norm-conserving pseudopotential for carbon and ultra-soft pseudopotential for hydrogen were used with the local density approximation (LDA) of PerdewZunger exchange and correlation (XC) function [26]. KohnSham equation [27] was solved to calculate energy with a kinetic energy cut-off of $340 \mathrm{eV}$. Only Gamma points were considered for all the calculations. The van der Waal forces were included using the Grimme dispersion model [28]. The total adsorption energy was then calculated as the summation of energy from self-consistent DFT and energy from dispersion correction. One unit cell consisted of one $\sim 13 \AA$ diameter and $11 \AA$ long armchair carbon nanotube

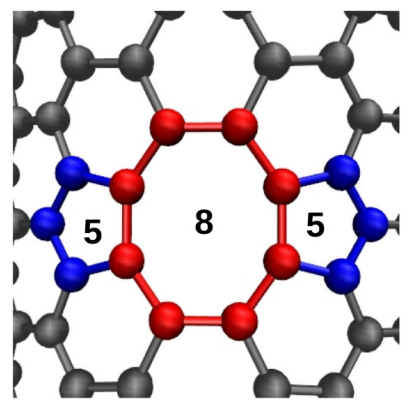

a

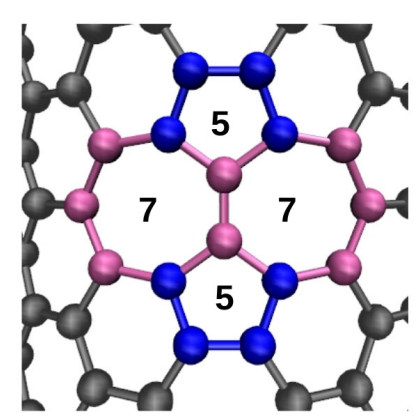

b

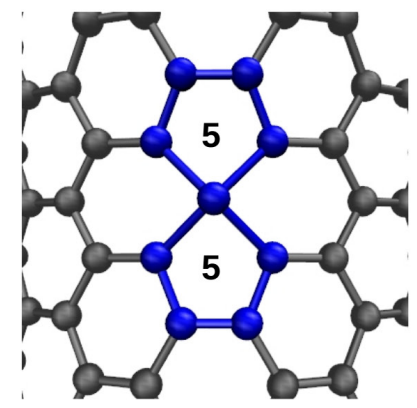

C



d

Fig. 1. (Color online) Four types of defective rings that have been considered D1: Stone-Wales 5, 8-membered defective rings (a), D2: StoneWales 5, 7-membered defective rings (b), D3: only 5-membered defective ring (c), and D4: 3-, 5-, 8-membered defective rings (d). Carbon atoms belonging to 3-, 5-, 6-, 7-, 8-membered rings are shown in orange, blue, silver, mauve and red colors.

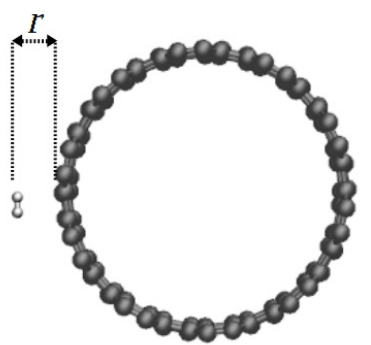

a

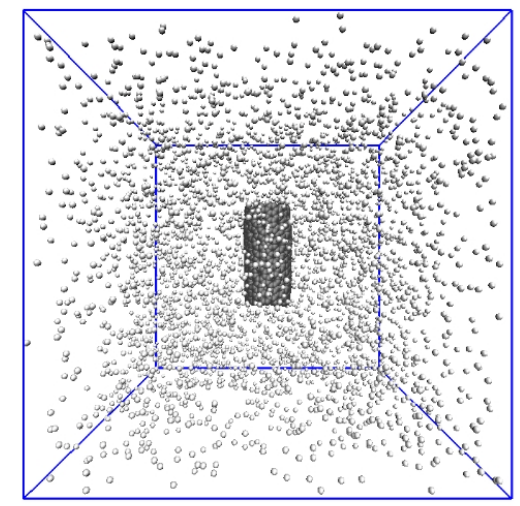

b

Fig. 2. System used in the DFT for calculating adsorption energies where $r$ is the equilibrium separation distance of hydrogen molecule from nanotube wall (a) and system used in the MD simulations (b). Carbon atoms are represented in gray and hydrogen molecules are represented in white. 
made of 200 carbon atoms and one hydrogen molecule as shown in Fig. 2 a. Adsorption energy $\left(E_{\text {adsorption }}\right)$ was calculated using the following equation:

$$
E_{\text {adsorption }}=E_{\mathrm{CNT}+\mathrm{H}_{2}}-\left(E_{\mathrm{CNT}}+E_{\mathrm{H}_{2}}\right) \text {, }
$$

where $E_{\mathrm{CNT}}$ is energy of CNT, $E_{\mathrm{H}_{2}}$ is energy of one free hydrogen molecule and $E_{\mathrm{CNT}+\mathrm{H}_{2}}$ is the energy of CNT with adsorbed $\mathrm{H}_{2}$. Energy of optimized geometry was considered in all cases.

\section{Results and discussion}

First, we considered armchair, chiral and zigzag defectfree SWCNTs to study the room temperature hydrogen adsorption in order to see the effect of chirality. Density profiles of hydrogen perpendicular to the major axis of SWCNT, $\rho(\mathrm{r})$, from the center of the SWCNT $(r=0)$ were calculated for armchair, chiral and zigzag SWCNTs of $\sim 13 \AA$ diameter at $298 \mathrm{~K}$ and $140 \mathrm{~atm}$ as shown in Fig. $3 \mathrm{a}$. (We found $13 \AA$ diameter is an optimum diameter for hydrogen storage, for more details see the Supplementary Material). In Fig. $3 \mathrm{a}, \rho(r)$ at $r<\sim 5 \AA$ represents the densities of $\mathrm{H}_{2}$ molecules which are inside the nanotubes and $\rho(r)$ at $r>\sim 8 \AA$ represents the densities of $\mathrm{H}_{2}$ molecules which are outside the nanotubes. The two peaks in Fig. 3 a show that $\mathrm{H}_{2}$ is adsorbed on the inner and outer surfaces of SWCNTs. We observed monolayer hydrogen adsorption both inside and outside the SWCNT for all three SWCNTs. Next, we calculated the amount of adsorbed hydrogen in wt.\%, plotted in Fig. 3 b. To estimate the adsorption amount, we considered the $\mathrm{H}_{2}$ molecules which are in the adsorbed layer of SWCNTs. The adsorbed layer is defined as the region under the peaks in the density profiles. We note that the hydrogen adsorption is not significantly affected by the chirality, clearly seen in Fig. 3 b, that shows that the gravimetric capacity is almost same for the three SWCNTs. Therefore, we considered only one type of SWCNT, armchair SWCNT of diameter $13 \AA$ to study the room temperature hydrogen adsorption in defective SWCNT.

Density profiles of hydrogen molecules for the defective SWCNTs are shown in Fig. 4. All the plots show monolayer adsorption for the SWCNTS of all types of defects which is in contrast with hydrogen adsorption in low temperature where the multilayer adsorption is observed [17]. Incorporation of defects leads to structural deformation in the wall of the nanotubes. The structural changes can be identified from the change in starting point of the adsorbed $\mathrm{H}_{2}$ layer both in the inner and outer surface of SWCNT. We note from the density profiles that SWCNT with D1 defect remains structurally unaltered upon defect incorporation. Except D1 defected SWCNTs, other three i. e., D2, D3 and D4 defected SWCNTs are significantly altered due to the incorporation of defects and the alteration increases with percentage defect $\left(\% D_{\mathrm{f}}\right)$. At higher $\% D_{f}, \mathrm{D} 3$ and D4 defected SWCNTs are structurally distorted to such an extent that the effective diameter of the SWCNTs decreases and hence, bulk $\mathrm{H}_{2}$ density inside the nanotubes could not be reached.

Fig. 5 shows how hydrogen adsorption varies with increasing percentage of defects compared to defect-free nanotube, where $\% D_{\mathrm{f}}=0$ indicates defect-free SWCNT. The wt.\% increases for SWCNTs with D1 defect, and wt.\% decreases for the SWCNTs with all other three defects i.e., D2, D3 and D4. The hydrogen adsorption capacity was found to be the lowest for the SWCNT with D4 defect.

In order to understand the discrepancies in the wt.\% for different defective SWCNTs, we calculated adsorption energies for various $n$-membered rings using DFT calculations. We note that the adsorption energies are different for different $n$-membered rings which lead to the discrepancies in the storage capacities. Eight-membered ring from D1 defect has the highest $E_{\text {adsorption }}$ and three-membered ring from D4 defect has the lowest $E_{\text {adsorption }}$ which is in line with the storage capacities of the defective SWCNTs.

\section{Conclusions}

The room temperature hydrogen storage capacity of four defective SWCNTs is thoroughly investigated using molecular dynamics simulations. At room temperature both the defectfree (pristine) and defective SWCNTS show monolayer adsorption inside and outside the nanotubes. We found that structural defects play a crucial role in hydrogen adsorption. Stone-Wales defect containing five- and eight-membered rings significantly increases hydrogen adsorption, whereas, presence of three-, five- and seven -membered rings decreases the adsorption capacity which is attributed to the difference in the adsorption energy of different $n$-membered

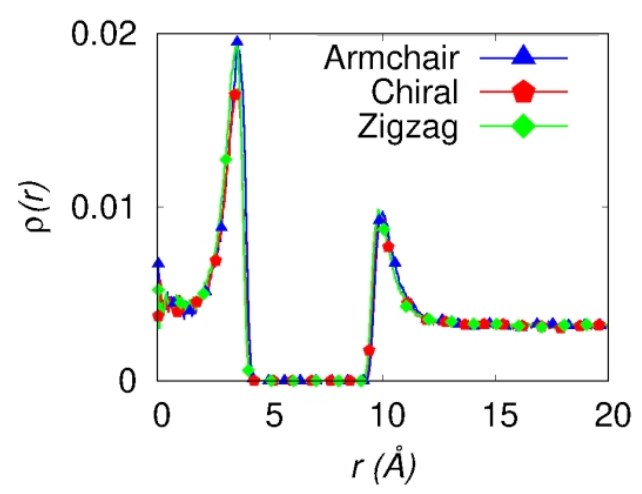

a



$\mathrm{b}$

Fig. 3. (Color online) Density profile of hydrogen molecules perpendicular to the major axis of SWCNT (a), and gravimetric hydrogen adsorption in wt.\% for armchair, chiral and zigzag SWCNT at room temperature (b). 




a

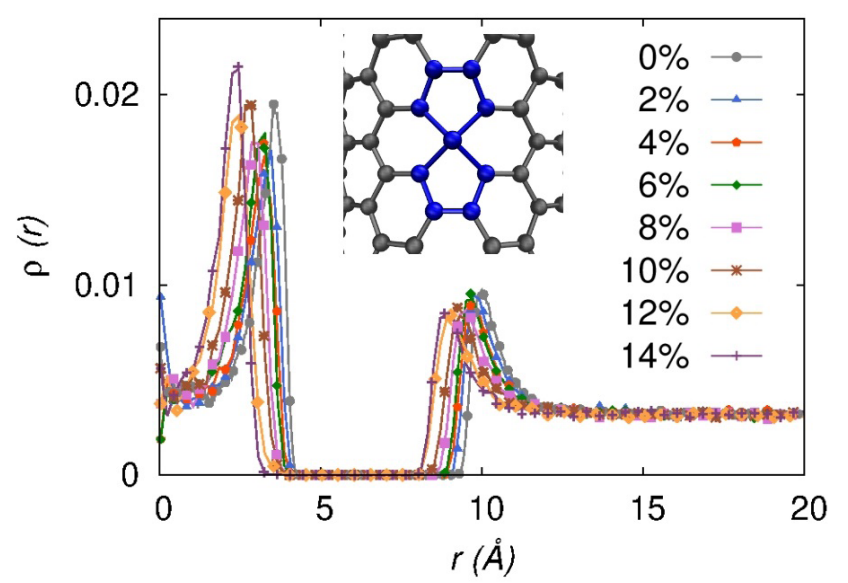

C

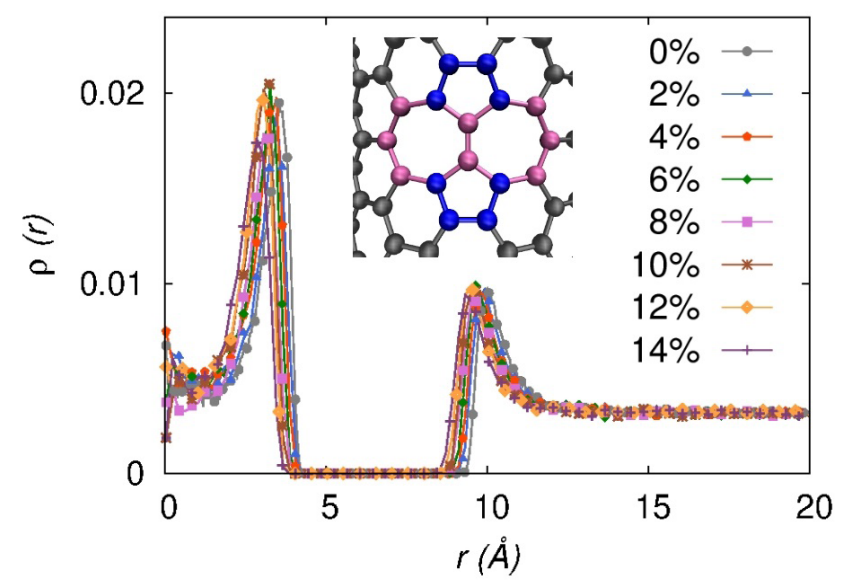

$\mathrm{b}$

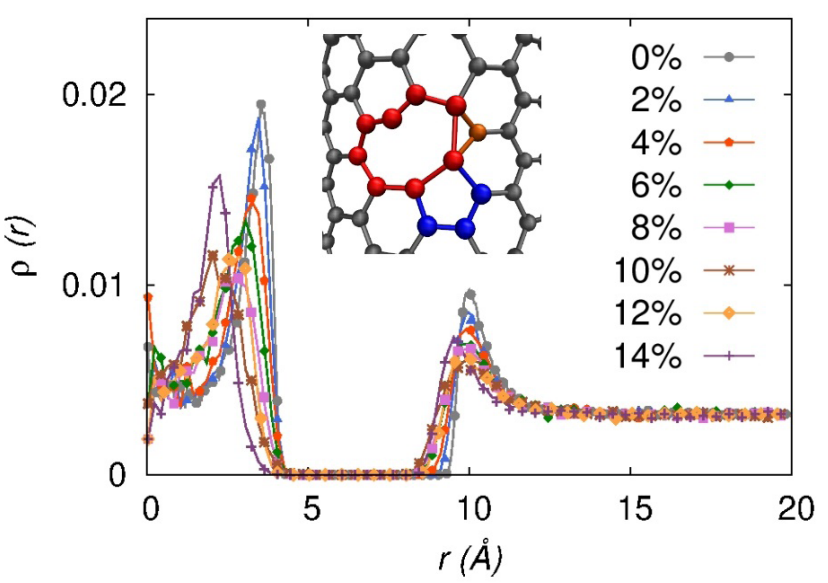

d

Fig. 4. (Color online) Density profile of hydrogen molecules perpendicular to the major axis of SWCNT as a function of percentage defect, $\% D_{\mathrm{f}}$ for D1: Stone-Wales 5-, 8-membered defective rings (a), D2: Stone-Wales 5-, 7-membered defective rings (b), D3: only 5-membered defective ring (c), and D4: 3-, 5-, 8-membered defective rings (d).

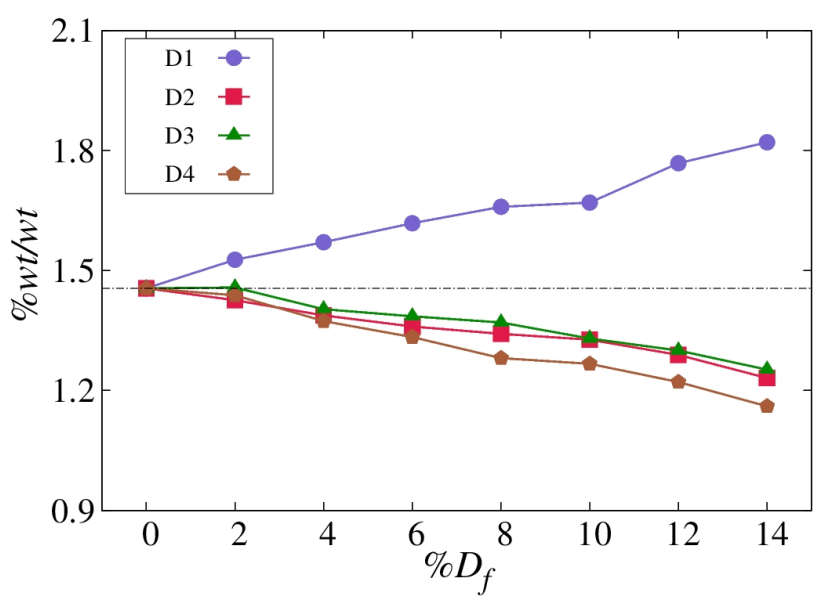

a

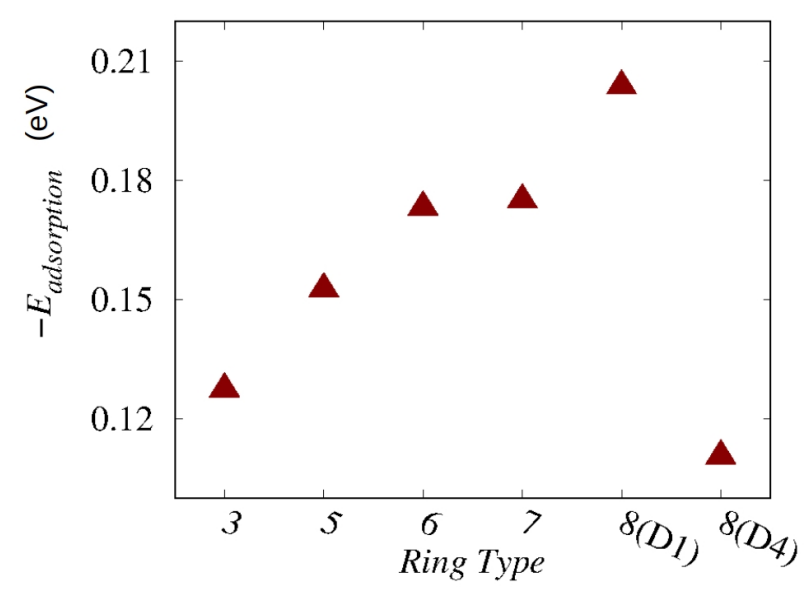

$\mathrm{b}$

Fig. 5. (Color online) Gravimetric hydrogen adsorption capacity, wt.\% of defective SWCNTs as a function of percentage defect, $\% D_{\mathrm{f}}$, at $298 \mathrm{~K}$ (a). Adsorption energy of different $n$-membered rings (b). 
carbon rings. The highest gravimetric capacity of 1.82 wt.\% at $298 \mathrm{~K}$ and $140 \mathrm{~atm}$ is found for the defective SWCNT with 5- and 8-member defective rings.

We stress that the defect induced surface modification can enhance the room temperature hydrogen adsorption which is attributed to the increase in the adsorption energy towards the hydrogen molecule. Therefore, our study suggests to propound surface modification in order to increase the adsorption energy which would lead us to reach the hydrogen adsorption goal even at room temperature.

Supplementary material. The online version of this paper contains supplementary material available free of charge at the journal's Web site (lettersonmaterials.com).

Author Contributions. M. G. and S. G. contributed equally to this manuscript.

Acknowledgements. We thank the department of chemical engineering, IIT Kharagpur for supporting the work.

\section{References}

1. Target explanation document: onboard hydrogen storage for light-duty fuel cell vehicles, tech. Rep., Office of Energy Efficiency and Renewable Energy (2017). Website

2. N.T. Stetson. Hydrogen storage program area plenary presentation, 2015. Annual merit review and peer evaluation meeting, fuel cell technologies office. U.S. Department of Energy (2015).

3. A.C. Dillon, T. Gennett, J.L. Alleman, K.M. Jones, P. A. Parilla, M. J. Heben. Carbon nanotube materials for hydrogen storage. In: Proceedings of the 2000 U.S. DOENREL Hydrogen Program Review (2000).

4. M.D. Allendorf, Z. Hulvey, T. Gennett et al. Energy Environ. Sci. 11, 2784 (2018). Crossref

5. S. Rostami, A. N. Pour, A. Salimi, A. Abolghasempour. Int. J. of Hydrog. Energy. 43 (14), 7072 (2018). Crossref

6. A. Ahmed, S. Seth, J. Purewal, A.G. Wong-Foy, M. Veenstra, A. J. Matzger, D. J. Siegel. Nat. Commun. 10, 1568 (2019). $\underline{\text { Crossref }}$
7. B. Szczesniak, J. Choma, M. Jaroniec. J. Colloid Interface Sci. 514, 801 (2018). Crossref

8. S. Palla, N.S. Kaisare. Int. J. of Hydrog. Energy. 45 (48), 25862 (2020). Crossref

9. M. Mohan, V.K. Sharma, E.A. Kumar, V. Gayathri. Energy Storage. 1 (2), e35 (2019). Crossref

10. A. C. Dillon, M. J. Heben. Appl. Phys. A. 72, 133 (2001). Crossref

11. R. Ströbel, J. Garche, P. T. Moseley, L. Jörissen, G. Wolf. J. of Power Sources. 159 (2), 781 (2006). Crossref

12. M. Elyassi, A. Rashidi, M.R. Hantehzadeh. J Inorg Organomet Polym. 27, 285 (2017). Crossref

13. S. Ghosh, V. Padmanabhan. Int. J. of Hydrog. Energy. 42 (38), 24237 (2017). Crossref

14. S. Ghosh, V. Padmanabhan. Diam. Relat. Mater. 77, 46 (2017). Crossref

15. D. Silambarasan, V.J. Surya, K. Iyakutti, K. Asokan, V. Vasu, Y. Kawazoe. Applied Surface Science. 418 A, 49 (2017). Crossref

16. K. A. Krylova, J. A. Baimova, I. P. Lobzenko, A. I. Rudskoy. Physica B: Condens. Matter. 583, 412020 (2020). Crossref

17. S. Ghosh, V. Padmanabhan. Diam. Relat. Mater. 59, 47 (2015). Crossref

18. L. G. Zhou, S. Q. Shi. Carbon. 41, 613 (2003). Crossref

19. A. J. Stone, D. J. Wales. Chem. Phys. Lett. 128, 501 (1986). Crossref

20. L. G. Zhou, S.Q. Shi. Appl. Phys. Lett. 83, 1222 (2003). Crossref

21. A. Hashimoto, K. Suenaga, A. Gloter, K. Urita, S. Iijima. Nature. 430, 870 (2004). Crossref

22. S. Plimpton. J. Comp. Phys. 117, 1 (1995). Crossref

23. P. Giannozzi et al. J. Phys.: Condens. Matter. 21 (39), 395502 (2009). Crossref

24. M. Oobatake, T. Ooi. Prog. Theor. Phys. 48 (6), 2132 (1972). Crossref

25. F. Darkrim, D. Levesque. J. Chem. Phys. 109 (12), 4981 (1998). Crossref

26. J. P. Perdew, A. Zunger. Phys. Rev. B. 23 (10), 5048 (1981). Crossref

27. W. Kohn, L. J. Sham. Phys. Rev. 140, A1133 (1965). Crossref 28. S. Grimme. J. Comput. Chem. 27, 1787 (2006). Crossref 